\title{
Valve-preserving aortic replacement: Does the additional repair of leaflet prolapse adversely affect the results?
}

\author{
Frank Langer, MD \\ Thomas Graeter, MD \\ Nikolaous Nikoloudakis, MD \\ Diana Aicher, MD \\ Olaf Wendler, MD \\ Hans-Joachim Schäfers, MD, PhD
}

From the Department of Thoracic and Cardiovascular Surgery, University Hospital Homburg, Germany.

Received for publication July 5, 2000; revisions requested Oct 11, 2000; revisions received Jan 22, 2001; accepted for publication Jan 25, 2001.

Read at the Twenty-sixth Annual Meeting of The Western Thoracic Surgical Association, The Big Island, Hawaii, June 21-24, 2000.

Address for reprints: Hans-Joachim Schäfers, MD, PhD, Chairman, Department of Thoracic and Cardiovascular Surgery, University Hospital Homburg, 66424 Homburg/Germany (E-mail: chhjsc@medrz.uni-sb.de).

J Thorac Cardiovasc Surg 2001;122:270-7

Copyright () 2001 by The American Association for Thoracic Surgery

$0022-5223 / 2001 \$ 35.00+0 \quad \mathbf{1 2 / 6 / 1 1 4 6 3 5}$

doi:10.1067/mtc.2001.114635
Objective: Valve-preserving aortic replacement has evolved into an accepted therapeutic option for aortic ectasia with morphologically intact leaflets. Some patients, however, exhibit additional leaflet prolapse. We compared the results of established valve-preserving techniques with those of the combination of valve-preserving aortic surgery and additional repair of leaflet prolapse.

Methods: Between October 1995 and March 2000, 99 patients underwent valvepreserving root replacement by means of root remodeling or valve reimplantation for acute dissection $(n=25)$, chronic dissection $(n=4)$, or aneurysm $(n=70)$. In group A (63 patients) either root remodeling $(n=49)$ or valve reimplantation $(n=$ 14) was performed with a standard technique. In group B (36 patients) valvepreserving aortic replacement (remodeling, $\mathrm{n}=31$; reimplantation, $\mathrm{n}=5$ ) was combined with repair of leaflet prolapse in the presence of bicuspid $(n=24)$ or tricuspid $(\mathrm{n}=12)$ valve anatomy. Additional replacement of the aortic arch was required more frequently in group $\mathrm{A}$ (group $\mathrm{A}, \mathrm{n}=43$; group $\mathrm{B}, \mathrm{n}=14 ; P=.006$ ); otherwise, the groups were comparable.

Results: Cardiopulmonary bypass (group A, $133 \pm 31$ minutes; group B, $117 \pm 30$ minutes; $P=.006$ ) and myocardial ischemia times (group A, $96 \pm 25$ minutes; group $\mathrm{B}, 88 \pm 20$ minutes; $P=.05$ ) were significantly longer in group A. Mortality was not significantly different between groups (group A, $4.8 \%$; group B, $0 \%$ ). One patient in each group underwent secondary valve replacement, and all other patients had stable valve function. Freedom from aortic regurgitation of grade 2 or greater after 48 months was $93.0 \%$ in both groups.

Conclusion: Repair of leaflet prolapse in conjunction with valve-preserving root replacement leads to midterm results that are equal to those of valve-preserving root replacement for morphologically intact leaflets.

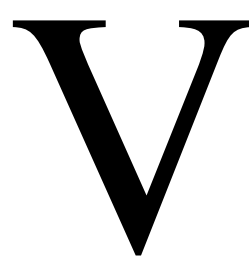

alve-preserving proximal aortic replacement has been proposed in different modifications ${ }^{1,2}$ and has become a promising alternative to composite replacement of valve and aorta. ${ }^{3,4}$ Regardless of differences in surgical technique, all variations of valvepreserving root replacement have been designed for patients in whom aortic regurgitation is solely caused by aortic root dilatation with morphologically preserved valve leaflets. Under these circumstances, leaflet coaptation is impaired by increasing diameters at the sinotubular level, aortoventricular level, or both. 


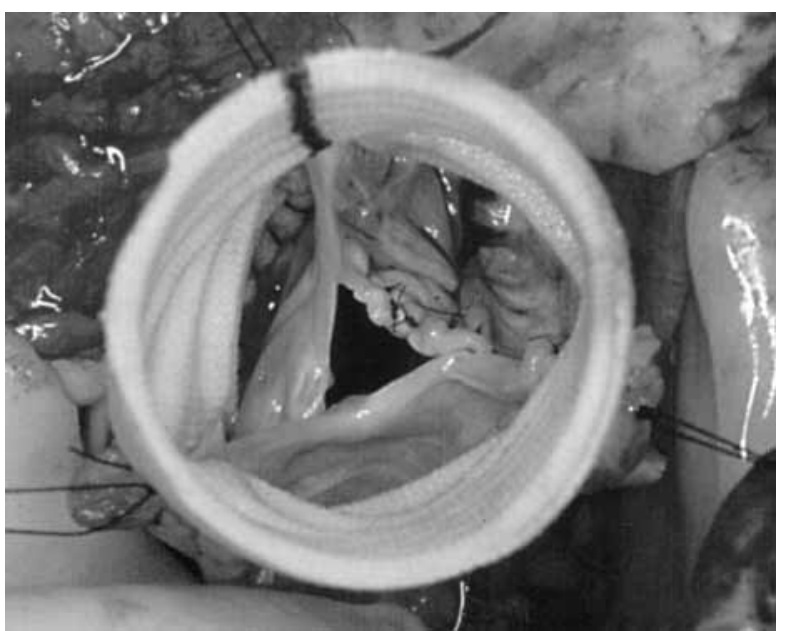

Figure 1. Operative situs. Plicating sutures (Prolene 5-0 or 6-0) were placed in the central portion of the free margin of an elongated leaflet until identical length of the leaflet margins was achieved.

Although this mechanism is responsible for valve dysfunction in many patients with root ectasia, leaflet defects may coexist with root dilatation in others. This may occur in the presence of tricuspid or bicuspid aortic valve anatomy. Currently, these patients are still treated by means of composite replacement by most surgeons, with the associated risks of thromboembolism, anticoagulation, and prosthetic valve endocarditis.

Isolated leaflet prolapse in tricuspid, and particularly bicuspid, aortic valves without concomitant aortic root dilatation is applicable to valve reconstruction, with encouraging results. ${ }^{5}$ Thus, it appears reasonable to assume that patients with aortic regurgitation caused by root dilatation and limited morphologic defects (ie, prolapse) of one or more aortic valve leaflets can be adequately treated with valve-preserving aortic operations. On the basis of our experience with traditional concepts of valve-preserving root replacement, ${ }^{6}$ we have extended the application of this approach. Facing leaflet prolapse, we have combined the techniques of leaflet prolapse repair with the established principles of root replacement. In this retrospective investigation we compared the midterm results of established valve-preserving root replacement alone with those of combined valve repair and valve-preserving aortic replacement.

\section{Patients and Methods \\ Patients}

Between October 1995 and March 2000, a total of 99 patients underwent valve-sparing operations for proximal aortic disease. The underlying aortic disease for elective operations was aneurysmal dilatation in 70 instances and chronic type A dissection in 4 patients. Twentyfive patients had to undergo emergency operations for acute type A
TABLE 1. Demographic data

\begin{tabular}{lccc}
\hline & Group A & Group B & P value \\
\hline $\mathrm{n}$ & 63 & 36 & \\
Age (y) & $64 \pm 17$ & $56 \pm 12$ & .0001 \\
Sex & & & \\
$\quad$ Male (n) & 37 & 26 & .2 \\
$\quad$ Female (n) & 26 & 10 & \\
Aortic pathology & & & \\
$\quad$ Aneurysm (n) & 42 & 28 & $>.2$ \\
$\quad$ AADA (n) & 18 & 7 & \\
$\quad$ CADA (n) & 3 & 1 & \\
Aortic valve anatomy & & & \\
$\quad$ Tricuspid (n) & 63 & 24 & \\
$\quad$ Bicuspid (n) & 0 & 12 & \\
\hline
\end{tabular}

$A A D A$, Acute type A dissection; CADA, chronic type A dissection.

dissection (22 patients with cardiogenic shock as a result of cardiac tamponade). Of the total patient population, a subgroup of 63 patients presented with aortic regurgitation caused by root dilatation in the presence of morphologically intact leaflets. In group B $(n=36)$ aortic regurgitation was caused by a combination of root dilatation and leaflet prolapse. Elongation of the free margin of aortic valve leaflets was found either in tricuspid anatomy $(n=12)$ or as elongation of the congenitally fused leaflet in bicuspid aortic valves $(n=24)$. Patients were older in group A, whereas sex was similarly distributed in both groups (Table 1). The preoperative degree of aortic regurgitation ranged from 1 to 4 and was similar in both groups (group A, $2.4 \pm$ 0.8 ; group $\mathrm{B}, 2.6 \pm 0.6 ; P=.2$ ). Concomitant coronary artery disease was present in 17 patients (group $\mathrm{A}, \mathrm{n}=13$; group $\mathrm{B}, \mathrm{n}=4 ; P=.2$ ); 2 of the patients in group A had previously undergone coronary artery bypass grafting. Mitral regurgitation was present in 5 patients in group A $(P=.2)$. The clinical stigmata of Marfan syndrome were observed in 5 patients in group A.

\section{Operative Technique}

In all patients the chest was opened by means of a median sternotomy, and the patients were begun on extracorporeal circulation by means of aortic and right atrial cannulation. After aortic crossclamping, cardioplegic arrest was induced by infusion of $\mathrm{St}$ Thomas Hospital solution directly into the coronary ostia. The aortic root was inspected carefully, and the diameters of the aortoventricular junction and the sinotubular junction were measured. Particular care was taken to assess the geometry of the aortic valve and leaflet morphology. If calcification was encountered, composite replacement was performed. Valve-preserving operations were only considered for pliable leaflet tissue; in those patients with leaflet prolapse, additional corrective measures were taken. The aortic wall was resected, including the sinus wall, to facilitate assessment of aortic valve and root geometry. In the presence of a tricuspid valve, a 7-0 Prolene suture (Ethicon, Inc, Hamburg, Germany) was passed through the noduli of Arantius, and the relative length of the free margins of all leaflets was estimated. If excessive length of the free margin of a leaflet was encountered ( $>3 \mathrm{~mm}$ ), this was reduced by shortening of the margin close to one or both commissures ${ }^{7}$ with 5-0 Prolene sutures early in this 


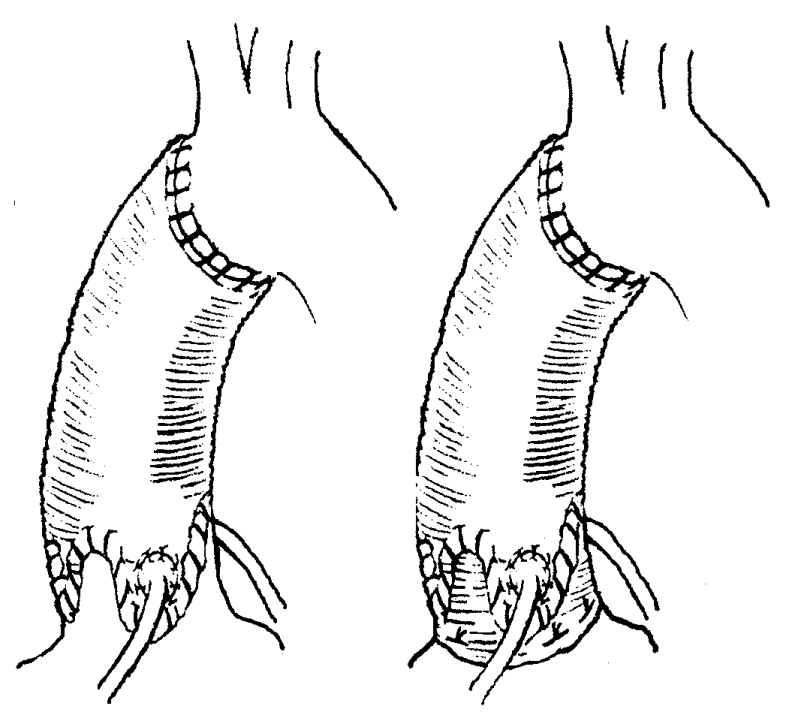

Figure 2. Schematic drawing of the 2 root procedures used. The remodeling procedure (left) primarily restores sinus configuration and sinotubular junction. Reimplantation of the valve within a vascular graft (right) additionally corrects dilatation of the aortoventricular junction. (From Schäfers H, Fries R, Langer F, Nikoloudakis N, Graeter T, Grundmann U. Valve-Preserving Replacement of the Ascending Aorta: Remodeling Versus Reimplantation. J Thorac Cardiovasc Surg. 1998;116:990-6).

series $(n=8)$. Later in the experience, one or several of these sutures (Prolene 5-0 or 6-0) were placed in the central portion of the free margin $(n=4)$ until identical length of the leaflet margins was achieved (Figure 1). In bicuspid aortic valves, radial tension was placed on the 2 commissures to assess leaflet prolapse. The free margin of the congenital fusion of the left and right coronary leaflets was found to be elongated, with resulting prolapse in all cases. A median raphe was present in most instances. The 2 parts of the fused leaflet were approximated at the center of the free margin by means of interrupted 5-0 Prolene sutures. Shortening of the leaflet margin was considered adequate if both leaflets were at identical heights after applying radial tension on the 2 commissures. Triangular resection of the median raphe ${ }^{5}$ with more extensive reapproximation of the 2 rudimentary leaflets was performed in 6 patients in whom calcifications of valve tissue in this particular area made direct suture adaptation difficult to achieve.

The choice of root procedure was primarily based on root anatomy: if moderate root dilatation was encountered predominantly at the sinotubular level (sinotubular diameter $3.5-5 \mathrm{~cm}$ ), remodeling of the aortic root was chosen $(n=80)$. For classic annuloaortic ectasia (sinotubular diameter $>5 \mathrm{~cm}$; aortoventricular diameter $>2.9 \mathrm{~cm})$ and Marfan syndrome $(\mathrm{n}=5)$, aggressive root replacement with reimplantation of the aortic valve was performed $(\mathrm{n}=19)$. This procedure was also used in patients with connective tissue defects, such as Marfan syndrome $(n=5)$.

For aortic root remodeling (Figure 2), graft size was chosen corresponding to the diameter of the aortoventricular junction. The Dacron graft (Unigraft; Unicare Biomedical, Inc, Melsungen, Germany) was then tailored, creating a sinus-like configuration corresponding to the geometry of the aortic root. ${ }^{1}$ In bicuspid valves the tailoring process had to accommodate the asymmetry of the root. ${ }^{8}$

For valve reimplantation (Figure 2), the aortic valve was mobilized to the level of the aortoventricular junction. The graft size was chosen according to the maximum height measured from the base to the free edge of the leaflets, leaving approximately $30 \%$ to $40 \%$ of leaflet height for coaptation. The graft was then anastomosed to the aortoventricular junction by transmural mattress sutures. Reimplantation of the native valve was performed by a standard technique. ${ }^{2}$

After root replacement, the graft was filled with saline solution, allowing for the assessment of leaflet coaptation and valve competence. If necessary, additional plicating sutures were placed at this time to correct any persisting prolapse. The coronary ostia were implanted in typical fashion. After completion of these anastomoses, the competence of valve and root suture lines was tested by application of cardioplegic solution into the graft. Concomitant procedures were performed when necessary (eg, coronary artery bypass operations, mitral valve reconstruction, or arch replacement under hypothermic circulatory arrest $\left[21^{\circ} \mathrm{C}\right.$ nasopharyngeal temperature for partial arch replacement and $18^{\circ} \mathrm{C}$ nasopharyngeal temperature for total arch replacement]). For aneurysmal disease with diffuse atherosclerotic debris, additional retrograde cerebral perfusion was applied during circulatory arrest.

\section{Echocardiographic Surveillance}

After discontinuation of cardiopulmonary bypass, transesophageal echocardiography was performed to assess aortic valve function (HDI 3000; Advanced Technology Laboratories, Bothell, Wash). The blood pressure was manipulated pharmacologically to maintain a diastolic level of $70 \mathrm{~mm} \mathrm{Hg}$ at the time of echocardiography. A semiquantitative assessment of the degree of aortic regurgitation was based on the intensity and slope of the regurgitation signal and the relative size of the regurgitation jet in relation to the left ventricular outflow tract. ${ }^{9-11}$ Postoperative transthoracic echocardiography was performed at discharge and after 3, 6, 9, 12, 24, and 36 months and every 12 months thereafter. All echocardiographic investigations were read by a single investigator using the same device. In addition to assessment of regurgitation, systolic flow gradients were recorded.

\section{Statistics}

All data were reviewed retrospectively. Mean values and standard variations were calculated (Excel; Microsoft, Verl, Germany). Statistical analyses were performed with Sigmastat software (SPSS Inc, Chicago, Ill). Discrete variables were analyzed with the Fisher exact test; the Mann-Whitney $U$ test was applied for continuous variables. Survival curves were calculated with Graphpad software (Graphpad Prism, San Diego, Calif), with log-rank tests for curve comparison.

\section{Results}

Remodeling of the aortic root was performed in 49 patients from group A, and reimplantation of the aortic valve was the root procedure in 14 patients from the same group. In group $\mathrm{B}$, remodeling was chosen in 31 patients, and 5 patients from this group underwent valve reimplantation. 
TABLE 2. Operative data

\begin{tabular}{lccc}
\hline & Group A & Group B & P value \\
\hline ECC time (min) & $133 \pm 31$ & $117 \pm 30$ & .006 \\
Myocardial ischemia time (min) & $96 \pm 25$ & $88 \pm 20$ & .05 \\
Root procedure & & & \\
$\quad$ Remodeling (n) & 49 & 31 & $>.2$ \\
$\quad$ Reimplantation (n) & 14 & 5 & \\
Arch replacement & & & \\
$\quad$ Partial (n) & 32 & 14 & .006 \\
$\quad$ Total (n) & 11 & 0 & .006 \\
CABG (n) & 13 & 4 & $>.2$ \\
MVPI (n) & 5 & 0 & .2 \\
\hline
\end{tabular}

$E C C$, Extracorporeal circulation; $C A B G$, coronary artery bypass grafting; $M V P I$, mitral valve reconstruction.

Prolapse of a single leaflet was found in 27 patients and corrected at the center of the leaflet (tricuspid, $\mathrm{n}=3$; bicuspid: plication, $\mathrm{n}=16$; triangular resection, $\mathrm{n}=3$ ) or at the commissure (tricuspid, $n=5$ ). A prolapse of 2 leaflets was corrected in 7 individuals at the leaflet center (bicuspid: plication, $\mathrm{n}=2$; triangular resection, $\mathrm{n}=3$ ) or close to the commissures (tricuspid, $n=2$ ). In 2 patients prolapse was encountered at all 3 leaflets and corrected at the level of the commissures.

Extracorporeal circulation time (group A, $133 \pm 31$ minutes; group $\mathrm{B}, 117 \pm 30$ minutes; $P=.006$ ) and myocardial ischemia (group A, $96 \pm 25$ minutes; group B, $88 \pm 20$ minutes; $P=.05$ ) were significantly longer in group A (Table 2).

Four patients (group A, $\mathrm{n}=3$; group $\mathrm{B}, \mathrm{n}=1 ; P=>.2$ ) required re-exploration for surgical bleeding. Perioperative atrioventricular conduction disturbance was not observed in any patient. One patient in each group required an intra-aortic balloon pump for treatment of low cardiac output. One patient in each group exhibited postoperative neurologic events. One patient in group A with acute type A dissection had paraparesis as a result of spinal ischemia, which resolved within the following months. The second patient had postoperative hemiparesis, which subsided within 3 weeks. Thromboembolic events were not noted in the postoperative follow-up. There was no evidence for endocarditis in any patient during follow-up.

Mortality (group A, 3/63; group B, $0 / 36 ; P=>.2$ ) was not significantly different between groups. Three patients in group A died in the hospital. Two of these patients underwent repair of acute type A dissection. One died as a result of a cerebral complication after cardiac arrest and cardiopulmonary resuscitation during induction of anesthesia. The other patient had an uneventful perioperative course but sustained fulminant pulmonary embolism 1 day before scheduled discharge. A third patient undergoing elective root remodeling and total arch replacement for extensive atherosclerotic aneurysm had fatal nonocclusive mesenteric ischemia.
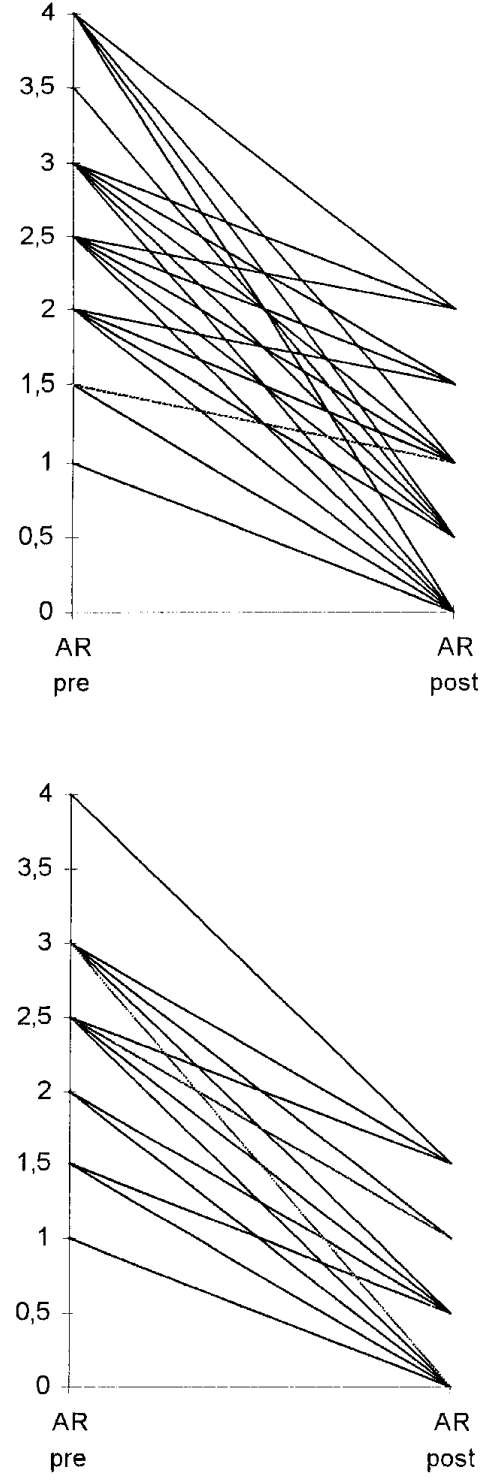

Figure 3. Reduction of degree of aortic regurgitation (AR), as determined by semiquantitative echocardiography. Top, Group A, bottom, group B.

Increasing aortic regurgitation led to reoperation in 2 instances 4 and 6 months postoperatively. One patient in group A with remodeling of the aortic root had secondary root dilatation at the aortoventricular junction, resulting in secondary aortic regurgitation. The other patient (group B) had undergone leaflet reconstruction with sutures close to the commissure for prolapse of all 3 leaflets, 2 of which were torn out at reoperation.

All other patients have had stable valve function documented with transthoracic echocardiography at a mean follow-up of 22.6 months (range, 1-53 months; median, 21 months; total of 2244 patient months). Aortic regurgitation 


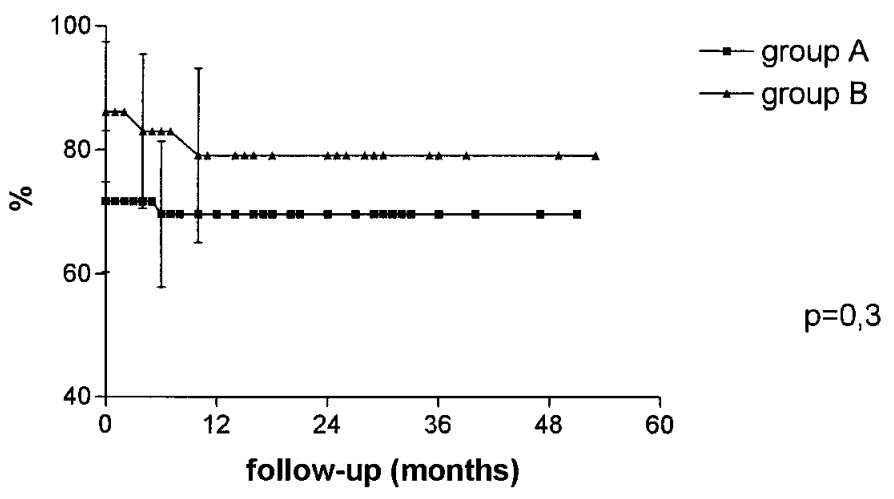

Individuals at risk

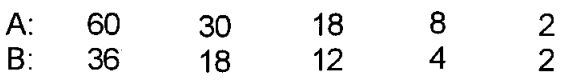

Figure 4. Freedom from aortic regurgitation of grade 1 or greater. Error bars represent $95 \%$ confidence intervals $(P>$.2).

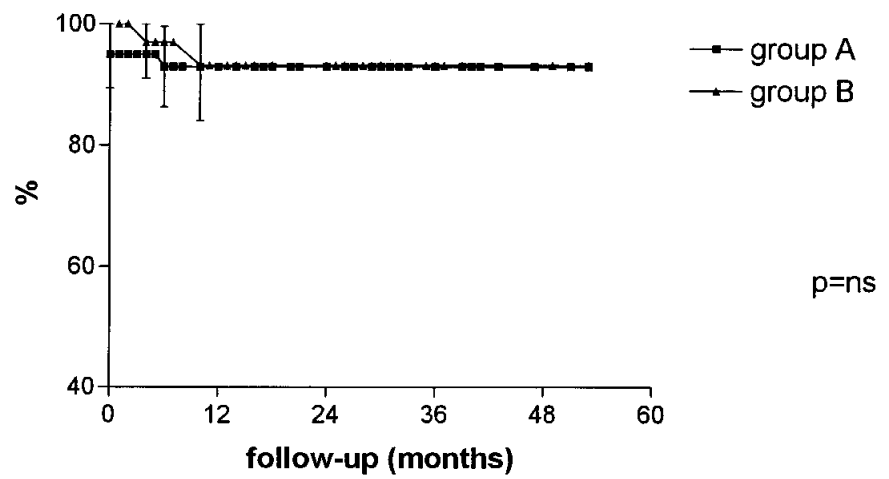

Individuals at risk:

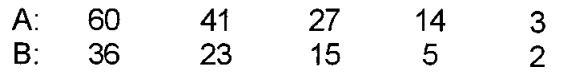

Figure 5. Freedom from aortic regurgitation of grade 2 or greater. Error bars represent $95 \%$ confidence intervals $(P>$.2).

was reduced from grade $2.4 \pm 0.8$ to grade $0.5 \pm 0.7$ in group A and from grade $2.6 \pm 0.6$ to grade $0.5 \pm 0.8$ in group $\mathrm{B}$, respectively (Figure 3). Freedom from aortic regurgitation of grade 1 or greater after 48 months (Figure 4) was $69.7 \%$ in group $\mathrm{A}$ and $79.1 \%$ in group $\mathrm{B}(P>.2)$. Freedom from aortic regurgitation of grade 2 or greater after 48 months (Figure 5) was $93 \%$ in both groups $(P>.2)$. Three patients in group A had aortic regurgitation of grade 2 after remodeling, without clinical signs of congestive heart failure. One of these patients had increased from grade 1 to grade 2 nine months postoperatively. Mean valvular gradients were higher in group B (group A, $3.9 \pm 2.3 \mathrm{~mm} \mathrm{Hg}$; group B, $5.5 \pm 2.2$ $\mathrm{mm} \mathrm{Hg} ; P=.01$ ) but still within the normal range (Table 3 ).

One patient in group B with a coronary anomaly (left anterior descending artery originating from the right coro- nary artery) had angina 9 months postoperatively. Repeat coronary catheterization revealed a new lesion at the left coronary artery, which was suspected to be due to intubation of the ostium for cardioplegia. The patient underwent an uneventful coronary bypass operation and has been asymptomatic since.

\section{Discussion}

Valve-sparing aortic replacement correcting root dilatation with aortic regurgitation has been propagated with encouraging results within the past decade. Two distinctive procedures have been described. Sarsam and Yacoub ${ }^{1}$ propagated the remodeling procedure of the aortic root to achieve coaptation by reduction of the sinotubular junction. This technique appreciates anatomy and function of the sinuses of Valsalva, which 
attribute to physiologic aortic valve function. Root stabilization is achieved at the level of the sinotubular junction, leaving the possibility of potential secondary dilatation at the aortoventricular junction. This has been observed in one of the patients requiring reoperation in our series.

The approach proposed by David and Feindel ${ }^{2}$ addresses this aspect. They found that in classic annuloaortic ectasia not only the sinotubular level but also the aortoventricular level and its fibrous structures (ie, fibrous trigone and membranous septum) may be involved in the dilating process. This is frequently encountered in patients with connective tissue defects, such as Marfan syndrome. ${ }^{12}$ These patients appear to benefit from root replacement with reimplantation of the aortic valve into a vascular graft, which is anchored to the aortoventricular junction.

Both valve-sparing procedures follow a common principle. They are designed for patients with morphologically intact aortic valve leaflets, in whom aortic regurgitation is solely caused by root dilatation. In case of additional morphologic leaflet defects (ie, leaflet elongation or calcification), however, exact valve geometry cannot be achieved by using only one of the root procedures mentioned above. These patients are currently not considered as candidates for valve-preserving root replacement by most surgeons.

Aortic valve reconstruction techniques have gained increasing interest within recent years. Different techniques have been proposed with different results. ${ }^{5,13-15}$ The largest series has been reported by Cosgrove and coworkers ${ }^{5,16}$ from the Cleveland Clinic group, ${ }^{17}$ with excellent intermediate results. Bicuspid valve anatomy in particular appears to facilitate leaflet reconstruction because only a single coaptation line has to be appreciated in contrast to the more complex interference of 3 coaptation lines in the tricuspid valves. ${ }^{18}$

For patients with morphologically intact leaflets, we have been able to achieve good results with both valvepreserving approaches, as determined by the individual root pathologic condition. ${ }^{6}$ With increasing experience in repair of leaflet prolapse, we have modified the initial application of the established root procedures. A combination of root procedure and direct leaflet reconstruction was chosen for adequate coaptation in patients with aortic regurgitation caused by both root dilatation and leaflet prolapse. Under the assumption that correction of leaflet prolapse will result in better restoration of aortic valve geometry, we anticipated improved long-term results of valve-sparing aortic replacement. Our early experience with this combined approach for bicuspid valve anatomy was reported recent$1 y .{ }^{8}$ On the basis of this experience, we have extended this approach to tricuspid valve anatomy. The current results in both anatomic situations appear sufficiently favorable at intermediate follow-up to pursue this approach further.

For leaflet reconstruction, we used established surgical principles of leaflet prolapse repair to correct excessive
TABLE 3. Echocardiographic determination of aortic valve function without (group A) and with (group B) repair of leaflet prolapse

\begin{tabular}{lccc}
\hline & Group A & Group B & P value \\
\hline Preoperative AR & $2.4 \pm 0.8$ & $2.6 \pm 0.6$ & .2 \\
Postoperative AR & $0.5 \pm 0.7$ & $0.5 \pm 0.8$ & $>.2$ \\
Postoperative mean valvular & $3.9 \pm 2.3$ & $5.5 \pm 2.2$ & .01 \\
$\quad$ & & & \\
\hline
\end{tabular}

$A R$, Degree of aortic regurgitation.

length of the free margin of a prolapsing leaflet. In bicuspid anatomy the free margin of the fused leaflet was approximated at the median raphe by means of interrupted 5-0 Prolene sutures. ${ }^{17}$ Triangular resection of a median raphe with more extensive reapproximation of the 2 rudimentary leaflets, as advocated by Cosgrove and colleagues, ${ }^{5}$ was avoided unless calcifications of valve tissue in the raphe area made direct suture approximation difficult to achieve to minimize secondary suture dehiscence. ${ }^{17}$ In tricuspid valve anatomy we initially placed plicating sutures close to the commissures, according to the method of Trusler and coworkers, ${ }^{7}$ with favorable results. When we found these sutures torn out at the only reoperation in group B, we abandoned this technique. Because maximum leaflet shear stress is close to the commissures, we then performed leaflet shortening at the central portion of the free margin, which is similar to the technique used in bicuspid aortic valves. Additional triangular resection of leaflet tissue, as suggested by Carpentier ${ }^{15}$ for tricuspid anatomy, was also omitted to avoid potential suture line dehiscence. Long-term clinical observations may show which of these reconstructive technique is most suitable, particularly in tricuspid aortic valves.

Some uncertainty remains because of the different prognoses of bicuspid and tricuspid aortic valves. A bicuspid aortic valve predisposes to degeneration ${ }^{19}$ but may appear normal throughout a lifetime. ${ }^{20}$ We have seen patients with well-preserved structure of bicuspid aortic valves up to the age of 70 years. Repair of leaflet prolapse for regurgitant but otherwise normal bicuspid valves appears justified if it reduces the risk of endocarditis compared with prosthetic valves. Additional aortic replacement abolishes the associated risk for aortic dilatation ${ }^{21}$ or dissection ${ }^{22,23}$ in individuals with bicuspid valves.

The functional results of a combination of leaflet reconstruction and established root procedures documented by echocardiographic follow-up are encouraging. Because of adequate stability of the aortic valve repair, the option of preserving the physiologic aortic valve function appears to be superior to that of prosthetic valves. Associated risks of prosthetic valve endocarditis and anticoagulation may be minimized or prevented. The determined gradients were 
within physiologic range and comparable with those of a stentless biologic valve but below the gradients of a stented xenograft. $^{24,25}$

We thus conclude that the addition of valve reconstruction to root replacement results in aortic valve function that is equal to classic application of valve-preserving operations with morphologically intact leaflets. Further observations will be necessary to judge the long-term fate of different modes of leaflet prolapse repair in this context.

\section{References}

1. Sarsam MA, Yacoub M. Remodeling of the aortic anulus. J Thorac Cardiovasc Surg. 1993;105:435-8.

2. David TE, Feindel CM. An aortic-valve sparing operation for patients with aortic incompetence and aneurysm of the ascending aorta. $J$ Thorac Cardiovasc Surg. 1992;103:617-22.

3. Mingke D, Dresler C, Stone CD, Borst HG. Composite replacement of the aortic root in 335 patients with aneurysm or dissection. Thorac Cardiovasc Surg. 1998;46:12-9.

4. Gott VL, Gillinov AM, Pyeritz RE, Cameron DE, Reitz BA, Greene PS. Aortic root replacement: risk factor analysis of seventeen-year experience with 270 patients. J Thorac Cardiovasc Surg. 1995; 109:536-44.

5. Cosgrove DM, Rosenkranz ER, Hendren WG, Bartlett JC, Stewart WJ. Valvuloplasty for aortic insufficiency. J Thorac Cardiovasc Surg. 1991;102:571-7.

6. Schäfers HJ, Fries R, Langer F, Nikoloudakis N, Graeter T, Grundmann U. Valve-preserving replacement of the ascending aorta: remodeling versus reimplantation. J Thorac Cardiovasc Surg. 1998; 116:990-6.

7. Trusler GA, Moses CAF, Kidd BSL. Repair of ventricular septal defect with aortic insufficiency. J Thorac Cardiovasc Surg. 1973; 66:394-403.

8. Schäfers H-J, Langer F, Aicher D, Graeter T, Wendler O. Remodeling of the aortic root and reconstruction of the bicuspid aortic valve. Ann Thorac Surg. 2000;70:542-6.

9. Masayuma TK, Kodama AK, Kitabatake A, Nanto S, Sato H, Uematsu M. Non-invasive evaluation of aortic regurgitation by continuouswave Doppler echocardiography. Circulation. 1987;73:460-6.

10. Galassi AR, Nihoyannopoulos P, Pupita G, Odwadara H, Crea F, McKenna WJ. Assessment of colour flow imaging in the grading of valvular regurgitation. Eur Heart J. 1990;11:1101-8.

11. Wilkenshoff UM, Kruck I, Gast D, Schroder R. Validity of continuous wave Doppler and colour Doppler in the assessment of aortic regurgitation. Eur Heart J. 1994;15:1227-34.

12. Roman MJ, Rosen SE, Kramer-Fox R, Devereux RB. Prognostic significance of the pattern of aortic root dilatation in the Marfan syndrome. J Am Coll Cardiol. 1993;22:1470-6.

13. Duran CMG. Aortic valve repair and reconstruction. Op Techn Cardiac Thorac Surg. 1996;1:15-29.

14. Haydar HS, He GW, Hovaguimian H, McIrvin DM, King DH, Starr A. Valve repair for aortic insufficiency: surgical classification and techniques. Eur J Cardiothorac Surg. 1997;11:258-65.

15. Carpentier A. Cardiac valve surgery-the "French correction." $J$ Thorac Cardiovasc Surg. 1983;86:323-37.

16. Fraser C, Wang N, Mee R, Lytle B, McCarthy P, Sapp S, et al. Repair of insufficient bicuspid aortic valves. Ann Thorac Surg. 1994;58:38690.

17. Casselmann FP, Gilinov AM, Akhrass R, Kasirajan V, Blackstone EH, Cosgrove DM. Intermediate-term durability of bicuspid aortic valve repair for prolapsing leaflet. Eur J Cardiothorac Surg. 1999;15:302-8.

18. Brewer RJ, Deck JD, Capat ID, Nolan SP. The dynamic aortic root: its role in aortic valve function. J Thorac Cardiovasc Surg. 1976;72:4137.

19. Mills P, Leech G, Davies M, Leatham A. The natural history of a nonstenotic bicuspid aortic valve. Br Heart J. 1978;40:951-7.
20. Fenoglio J, McAllister H, DeCastro CD, Davia J, Cheitlin M. Congenital bicuspid aortic valve after the age 20. Am J Cardiol. 1977;39:164-9.

21. Pachulski RT, Weinberg AL, Chan KL. Aortic aneurysm in patients with functionally normal or minimally stenotic bicuspid aortic valve. Am J Cardiol. 1991;67:781-2.

22. Larson EW, Edwards WD. Risk factors for aortic dissection: a necropsy study of 161 cases. Am J Cardiol. 1984;53:849-55.

23. Edwards WD, Leaf DS, Edwards JE. Dissecting aneurysms associated with congenital bicuspid aortic valve. Circulation. 1978;57:1022-5.

24. Thomson HL, O'Brien MF, Almeida AA, Tesar PJ, Davison MB, Burstow DJ. Haemodynamics and left ventricular mass regression: a comparison of the stentless, stented and mechanical aortic valve replacement. Eur J Cardiothorac Surg. 1998;13:572-5.

25. Fries R, Wendler O, Schieffer H, Schäfers HJ. Comparative rest and exercise hemodynamics of $23 \mathrm{~mm}$ stentless versus stented aortic bioprosthesis. Ann Thorac Surg. 2000;69:817-22.

\section{Discussion}

Dr Manly R. Hyde (Los Angeles, Calif). You have retrospectively compared 2 groups of patients. The first group, who had root dilatation and morphologically intact leaflets by means of either the root remodeling or valve reimplantation techniques, underwent valve-preserving root replacement. The second group had additional correction of aortic leaflet prolapse by placing shortening sutures close to the commissures or, later in the study, in the midportion of the prolapsing leaflet. Triangular resection was also used in some patients. You reported comparable midterm results between the 2 groups, with a mean follow-up of 22.6 months.

Freedom from aortic regurgitation of greater than or equal to $1+$ was $69.7 \%$ in group A and $79.1 \%$ in group B. Freedom from aortic regurgitation of equal or greater than $2+$ after 48 months was $93 \%$ in both groups.

My main area of concern has to do with the long-term durability of the repair. Because only 19 patients, 14 in group A and 5 in group B, actually had reimplantation of the aortic valve, which in itself has a risk of distorting the normal commissural supporting anatomy, it is unclear from the small numbers and short follow-up whether concomitant repair of leaflet prolapse in these patients does have comparable long-term durability.

In addition, Casselman and associates have reported their experience from The Cleveland Clinic on the repair of bicuspid aortic valves with leaflet prolapse. In those patients followed up for up to 9 years, freedom from reoperation fell to $84 \%$ at 7 years. The only risk factor for reoperation was the presence of residual aortic regurgitation. They concluded that any residual regurgitation jeopardizes repair durability.

My first question is as follows: Are you concerned that the $20 \%$ to $30 \%$ of your patients that had $1+$ or greater regurgitation may have progression in the regurgitation resulting in reoperation, as suggested by Casselman and associates, or a decrease in left ventricular function over the long term?

Dr Langer. Thank you for the question. We have made similar observations that led us to do more leaflet correction later in the series. In our learning curve we have realized that a near-perfect geometry of the aortic valve is very important for long-term durability of these reconstructed valves. Therefore, I totally agree that we should aim for a near-perfect geometry.

Dr Hyde. Second, what is your opinion on the creation of pseudosinuses by scalloping the graft, which has a theoretical advan- 
tage of reducing stress on the leaflets, versus the technique of reimplanting the valve within a tube graft?

Dr Langer. There is a continuous discussion on possible thickening of valve leaflets in reimplantation. We actually have not seen that. Our reimplantation procedures work out quite well, and we have not had to reoperate after any of the reimplantation procedures.

Dr Hyde. In what percentage of your total aortic root replacements during this period were you able to preserve the aortic valve?

Dr Langer. Valve-preserving root replacement was performed in $62 \%$ of the patients referred with aortic regurgitation and dilatation of the ascending aorta.

Dr Hyde. Finally, do you think that the average cardiothoracic surgeon should be performing your valve-preserving techniques?

Dr Langer. The advantages of this technique are to prevent exposing the patient to the associated risks of aortic replacement, such as thromboembolism, anticoagulation, and prosthetic valve endocarditis. It may be an important tool for the cardiothoracic surgeons of tomorrow.

Dr Craig Miller (Stanford, Calif). Dr Langer, your boss, H. J. Schafers, and I have been debating these results for the last year or two at various meetings around the world, and I keep teasing him that this is too good to be true. He almost admits that, but as you have stated, the results are short term, and there is much more to be learned in the future. I rise for 2 points-one technical question and comment and another word of caution.

In terms of whether you are shortening the free margin, I think that is something all of us are not doing often enough. My personal series consists of only 50 cases, about half as many as yours. In a personal series of about 50 cases, the vast majority are reimplantations, operative procedures propogated by Tirone David. How do you define the level of coaptation, and how did you therefore define prolapse? When should you shorten the free margin to elevate or bring up the coaptation level higher into the root? I think your technique of reefing the noduli Arantius in the middle of the leaflet is very superior to the old Trusler stitch, but when do you do that, and how do you define prolapse?

Dr Langer. Before we actually go for the reimplantation technique with the graft, we put a 7-0 Prolene stitch through the noduli Arantius and then estimate the certain prolapse of the leaflet. The second thing is actually the size of the graft. Graft size is estimated according to the leaflet height, therefore leaving $30 \%$ to $40 \%$ for coaptation.

Does this answer your question?

Dr Miller. No, but that is okay. You brought up another point. How do you pick the size of the graft?
Dr Langer. For root remodeling, we choose graft size according to the aortoventricular junction, and for reimplantation, we choose according to the maximal height of the leaflet.

Dr Miller. The word of caution is the Yacoub or Tirone David 2 remodeling procedure, which the majority of your patients had, correct?

Dr Langer. Yes.

Dr Miller. Well, Tirone himself has abandoned the Tirone David procedure, especially in cases of Marfan syndrome with a large aortic anulus, for 2 reasons. First, there is too much late recurrent aortic regurgitation; second, there is too much intraoperative bleeding. All of us think it saves a suture line, and it does, but all the suture lines are exposed to atmosphere and that does lead to bleeding. He has abandoned it. Even if you look at Sir Magdi's report in Circulation in November 1999 for Marfan syndrome, he has a $17 \%$ reoperation rate at 5 years, which most of us would deem unacceptable: $47 \%$ of the patients have grade 1 aortic regurgitation at the time of last follow-up, and $25 \%$ have moderate or more significant aortic regurgitation. What do you think your results will show as your follow-up gets longer, and will they indeed stand the test of time when these other very experienced masters are already backing away from the remodeling procedure?

Dr Langer. Actually, there are 2 reasons for these long-term failures. One point is graft dilatation, and we did not see that. The second point is that the initial repair should be as adequate as possible. This is why we tended to be more aggressive with leaflet correction to achieve a perfect geometry of the valve, hoping to achieve longer durability.

Dr Miller. In the hands of your boss, Hans Schafers, we look forward to more long-term results.

Dr Edward Verrier (Seattle, Wash). I would like to pursue the same type of discussion a bit further. Twenty-six of your patients had dissections of one sort or the other. Did any of those patients end up with a triangular resection to get better coaptation?

Dr Langer. Twenty-five patients underwent emergency operations. Triangular resection was not used in this series. We try to avoid triangular resection as much as possible. If you look at the results from the Cleveland Clinic group for bicuspid valves, a reason for reoperation has been triangular resection. We also avoid triangular resection in acute type A dissection.

Dr Verrier. Did any of the patients in this series have Marfan syndrome, and do you advocate doing valve-sparing operations like this in patients with Marfan syndrome?

Dr Langer. There are 5 patients with Marfan stigmata. They are included in group A, and therefore we did not see any patients with Marfan syndrome with limited leaflet prolapse. 